\title{
Vehicle Routing, Scheduling and Decision Utility Environment
}

\author{
Ceyhun Ozgur \\ Valparaiso University \\ Claire Okkema \\ Valparaiso University \\ Yiming Shen \\ Valparaiso University
}

\begin{abstract}
In this paper, we will try to summarize research on vehicle scheduling and decision utility. We assume a given framework with centralized management distribution system replenishment and given sets of distribution centers. We provide a solution to the issues of how vehicles can be scheduled or routed to achieve a company's logistic objectives. The problem, as typically formulated, is to determine the order turn in which the customers will be visited by delivery or pick-up vehicles otherwise called the route. Lastly, we discuss the facets of priority class scheduling in decision utility management and its advantages.
\end{abstract}

Keywords: Vehicle Scheduling, Vehicle Routing, Traveling Salesman Problem, TSP, Decision utility, Parks Management, Police Station Management

\section{INTRODUCTION}

Problems commonly presented in vehicle scheduling include: (1) the determination of the adequate number of vehicles; (2) the frequency with which each customer should be visited and (3) the times to be associated with the actual stops along the route. Our approach to vehicle routing and scheduling is to first present the idea of the Travelling Salesman Problem (TSP) (Goel, 2009). TSP is an analytic framework designed to solve scheduling problems. We then consider solution methodologies and further examine some actual operating complications. Some of the difficulties using vehicle scheduling problems include: (1) garbage route collection system that involves TSP; (2) lawn-mowing system for parks and recreation using TSP; (3) scheduling of like-products with automated assembly line and sequence dependent setups; and (4) scheduling like-items in a police station (Ozgur, 1990).

We assume a given system for distribution center (DC) replenishment and a given set of DCs, and ask: How should vehicles be best scheduled to achieve logistics objectives? The problem, as typically formulated, is to determine the order in which customers will be visited by delivery/pickup vehicles, often called the route. Other questions include determination of the proper number of vehicles, the frequency with which each customer should be visited, and the times to be associated with the stops along the route (Brown, 1986).

\section{Traveling Salesman Problem (Scheduling methods for a capacity constrained work} center and automated assembly line with sequence dependent setups)

The Traveling Salesman Problem can be easily stated but often, difficult to solve. The problem is given as a set of DCs to be visited. What is the least cost or distance method of visiting each 
city once, only starting from the same city and returning to it? The solution is that the starting and ending city could be a central facility or location (Adler \& Mirchandani, 2017).

\section{Examples of TSP}

There are many examples of TSP, listed below.

1. Optimal schedule of three different types of products for cable assembly in automobile production in a Single Machine Sequence Dependent Scheduling Problem

2. Optimal moving of grass in a given area, considering starting and ending points and the routing in the process.

3. Optimal garbage pick-up in a given city; it is important to determine the beginning and ending locations within the city and the routing in between.

4. Optimal schedule and consideration of change in colors of a product among three different colors in a paint production system.

5. Optimal truck scheduling for a company in charge of logistics and distribution of various products based on beginning and ending locations, and most importantly, the route in between.

4. (Ozgur, 1990)

\section{Solution Methodologies}

The Traveling Salesman Problem can be formulated as zero-one integer programming problem. Optimal solution approaches include branch and bound procedures similar to those discussed for distribution centers (DC) location problems and dynamic programming problems. Producing optimal solution procedures becomes computationally costly and the size of the problem goes up with the increase in the number of nodes or cities; in other words, as the size of the problem goes up, the number of distribution centers increases and the computational cost goes up geometrically (Bodin \& Golden, 1981).

Heuristic procedures have been devised for this problem that produce reasonably good results in far less time than the optimal procedures. One widely used is based on a time-saved concept. The basic consideration is the time or distance that would be saved if the two distribution centers were visited in a single tour as opposed to visiting each separately on a different tour (Ozgur, 1990).

\section{Decision Utility}

Decision utility approach is a method of balancing the amount of work to be done and the resources available. Usually, present work almost always exceeds the resources on-hand, resulting in routine performance measurement. The importance of measuring performance is the comparison of the number of products produced and the number of products that ideally would have been produced given the available resources (Komijan \& Delavari, 2017).

One facet of the decision utility approach is priority class scheduling. This method focuses on the creation of a framework that reduces conflict in a manufacturing environment. The framework's foundation utilizes the production period, and all jobs are classified into priority classes based on both their due dates and importance. The priority classes are used by the production scheduler as constraints on what can be scheduled in a production period. Brown and Ozgur state that "priority class scheduling rewards manufacturing for making small improvements in efficiency, involves marketing in the setting of production priorities, improves customer service by putting in place realistic production timetables, and improves both the communication and cooperation between the shop floor, the production scheduler, marketing, and customer service." (Brown \& Ozgur, 2010). 
One study suggested using priority class scheduling to reduce due date conflicts between marketing and the production schedulers by replacing due dates with production periods and priority classes (Brown and Ozgur, 2010). If any job in priority class $i-1$ is started in the production period, then all jobs in priority class $i-1$ must be completed within the production period. This is the only constraint on the production scheduler and allows the scheduler to concentrate on optimizing manufacturing efficiency within the production period. The constraint is so simple that its consequences are easily understood by those who assign jobs to priority classes, but at the same time, allows manufacturing some flexibility in scheduling (Brown \& Ozgur, 2010).

For example, the production scheduler can schedule a priority three job to be completed early in the production period as long as all priority one and priority two jobs are completed within the production period. In addition, if only some priority three jobs can be completed in the production period, the selection of which jobs to produce is made entirely on the basis of production efficiency. This gives some flexibility to manufacturing to optimize production efficiency. The production scheduler only considers the priority classes when scheduling and does not even need to know the due dates of the jobs. This means that marketing alone without any help from the production schedulers could determine the priority class for each job and let the production schedulers concentrate on increasing production efficiency (Brown \& Ozgur, 2010).

Short term physical changes could cause the violation of the priority class scheduling rules. For example, suppose a priority class three job was lumped together with a priority class one job early in the production period to reduce setup time and cost. If later in the production period a machine broke down and caused a priority class two job to not be run, then at the end of the production period, a priority class three job was completed, while a priority class two job was not completed. This is a clear violation of the idea of priority classes (Brown \& Ozgur, 2010).

Theoretically, priority class scheduling would greatly reduce the conflict between marketing and manufacturing. However, getting the production schedulers to agree to even try priority class scheduling would be very difficult, because of some of the problems listed above. The production schedulers would perceive a loss of job control, because they would feel that marketing would be dictating their jobs to them. With marketing in control of the "due dates," manufacturing would think that getting an efficient schedule would be impossible and the company would lose money (Brown \& Ozgur, 2010).

\section{Applications of Decision Utility in Park Systems}

Although many quantitative scheduling techniques are designed for production scheduling, other types of scheduling problems have been studied but they have some of the same obstacles listed above for production scheduling. For example, consider the problem of scheduling jobs in a governmental agency where the amount of work to be done almost always exceeds the resources available. In this case, the scheduling problem is deciding how much of each job to do and not do given the amount of resources on hand. For example, in the summer, a parks maintenance district must tradeoff how the number of times jobs like tractor mowing (mowing large open areas), trim mowing (mowing small areas around trees, sidewalks, buildings, etc.), litter removal, and ball field dragging are done in each park (Ozgur, 2018).

The main problem is to determine the correct balance between the jobs given and the resources available. This is clearly a case where a balance is necessary, because doing a lot of litter removal and ball field dragging while doing no mowing would not be acceptable to the 
tax payers. Decision utility can implement formulas that solve problems containing tasks rather than products (Brown, 1986). In addition, measuring performance, or considering what to do with information on what was actually accomplished with the resources available, is routinely done in manufacturing and decision utility. The importance of measuring performance is the comparison of the number of products produced and the number of products that ideally would have been produced given the available resources.

Table 1: Constrained Choice Table for Parks Maintenance Example

\begin{tabular}{|cc|c|c|c|c|c|c|c|c|}
\hline & DESIRABLE & \multicolumn{4}{c}{ PERCENT OF DESIRABLE QUANTITY } \\
ATTRIBUTES & QUANTITY & $\mathbf{0}$ & $\mathbf{1}$ & $\mathbf{2}$ & $\mathbf{3}$ & $\mathbf{4}$ & $\mathbf{5}$ & $\mathbf{6}$ \\
\hline 1.Trim Mowing & 20 Mowings & 0 & 10 & 40 & 50 & 80 & 100 & 100 \\
\hline 2.Tractor Mowing & 20 Mowings & 0 & 50 & 70 & 90 & 100 & 100 & 100 \\
\hline 3.Litter Removal & 10 Removals & 0 & 20 & 50 & 80 & 90 & 100 & 120 \\
\hline 4.Ballfield & 100 Draggings & 0 & 0 & 0 & 20 & 50 & 100 & 160 \\
Dragging & Totals & 0 & 80 & 160 & 240 & 320 & 400 & 480 \\
& UTILITY & $\mathbf{0}$ & $\mathbf{2 0}$ & $\mathbf{4 0}$ & $\mathbf{6 0}$ & $\mathbf{8 0}$ & $\mathbf{1 0 0}$ & $\mathbf{1 2 0}$ \\
\hline
\end{tabular}

Table 1 (Ozgur, 2018) displays the best balance between the jobs as it maximized the maximin value function given the resource constraints. The parks manager (PM) is asked to give how many times each job should be done to keep the parks in good condition, seen in the "Desirable" column. In the following columns, the percentages reflect the PM's tradeoffs between the four attributes and contain what he considers the best balance between them given the percentages can only sum to 80 .

\section{Application of Decision Utility in Police Stations}

Consider the problem of scheduling police officers in a police department where the amount of work to be done almost always exceeds the resources available in a given time period such as summer months. In this case, the scheduling problem is deciding how much of each type of job to do and still protect the public and ensure public safety given the amount of resources on hand for the entire summer months. For each police scheduling period, the police chief uses a data list of the police officers and estimates of the time for a police officer or police car to complete each job in the city, and what additional personnel and equipment was available and needed by the police department for each police activity. A computer schedule was run every two weeks and gave the police chief or the police supervisor an amount of each job the city could accomplish in the next two weeks with the resources predicted to be available (Ozgur, 2018).

Table 2: Constrained Choice Table for City Police Departments

\begin{tabular}{|cccc|c|c|c|c|c|c|}
\hline & DESIRABLE & \multicolumn{1}{c|}{ PERCENT OF DESIRABLE QUANTITY } \\
ATTRIBUTES & QUANTITY & $\mathbf{0}$ & $\mathbf{1}$ & $\mathbf{2}$ & $\mathbf{3}$ & $\mathbf{4}$ & $\mathbf{5}$ & $\mathbf{6}$ \\
\hline 1.Foot Patrol & 20 Officers & 0 & 10 & 40 & 50 & 80 & 100 & 100 \\
\hline 2.Car Patrol & 20 Cars & 0 & 50 & 70 & 90 & 100 & 100 & 100 \\
\hline $\begin{array}{c}\text { 3.Detective } \\
\text { Analysis }\end{array}$ & 10 Detectives & 0 & 20 & 50 & 80 & 90 & 100 & 120 \\
\hline 4.0ffice Work & & & & & & & & \\
\hline & 10 Officers & 0 & 0 & 0 & 20 & 50 & 100 & 160 \\
\hline & Totals & 0 & 80 & 160 & 240 & 320 & 400 & 480 \\
& UTILITY & $\mathbf{0}$ & $\mathbf{2 0}$ & $\mathbf{4 0}$ & $\mathbf{6 0}$ & $\mathbf{8 0}$ & $\mathbf{1 0 0}$ & $\mathbf{1 2 0}$ \\
\hline
\end{tabular}


Table 2 (Ozgur, 2018) displays how much foot or car patrol should be completed in lieu of office work or detective analysis in a period in a police district. A police chief is asked to give how many times each job should be done to keep the city, and its streets or roads safe in good condition, observed in the "Desirable" column. The following columns show the percentages that reflect the police chief's tradeoffs between the four attributes and contain what he/she considers the best balance between them given the percentages can only sum to 80 .

\section{CONCLUSION}

Regarding parks and police system utility management, there are several advantages to consider. Preferences are inputted to the model used to determine the best amounts of each attribute to accomplish given the resources available. In addition, decision utility management is easily understandable, as the quantitative scheduling algorithm determines the schedule. "What if" questions can also be answered in the algorithm. The utility management system is unbiased, as computer scheduling only gave the amounts of each job that could be accomplished and did not tell the parks manager/police chief what personnel should be assigned to which job.

The biggest advantage is that programming remains autonomous. Managers are free to devise his/her own work schedule and could not blame any inefficiencies on the computer schedule. They are also free to respond to both short term physical changes and priority changes as he/she saw fit. These advantages summarize why vehicle scheduling and decision utility management are an integral and beneficial factor in a workforce. With a plethora of applications, the two frameworks organize and help keep public services intact.

\section{References}

Adler, J., \& Mirchandani, P. (2017). The vehicle scheduling problem for fleets with alternative-fuel vehicles. Transportation Science, 51(2), 441-456. doi.org/10.1287/trsc.2015.0615

Bodin, L. and Golden, B. (1981). Classification in vehicle routing and scheduling. Networks, 11, 97-108. doi.org/10.1002/net.3230110204

Brown, J. (1986). Decision utility. (Unpublished paper).

J. R. Brown \& C. O. Ozgur (2010) Priority class scheduling: Production scheduling for multi-objective environments, Production Planning \& Control, 8:8, 762-770, DOI: $\underline{10.1080 / 095372897234650}$

Goel, A. (2009). Vehicle Scheduling and Routing with Drivers' Working Hours. Transportation Science, 43(1), 1726. doi.org/10.1287/trsc. 1070.0226

Komijan A.R., D. Delavari. (2017). Vehicle routing and scheduling problem for a multi-period, multi-perishable product system with time window: A case study. International Journal of Production Management and Engineering, $5(2), 45-53$.

Ozgur, C. (2018). Resources in parks and police management: Applying decision utility to solve problems with limited resources. International Journal of Information Systems in the Service Sector 10(2), 69-78. doi.org/10.4018/IJISSS.2018040105

Ozgur, C. (1990). Scheduling methods for a capacity constrained work center and automated assembly line with sequence dependent setups. (Unpublished Dissertation) 